\title{
Inquiry-Based Learning in Architecture
}

\author{
Luise Albrecht
}

Reform is needed in architectural education: The complexity of building tasks (new materials, new standards, internationalization, etc.) needs to be practiced more during training. Taking the path of supplementing the course of studies with special subjects does not seem promising; architectural studies would become overloaded and inaccessible to study. Inquiry-based learning offers an alternative: Students implement their own research projects (often with practice partners) and, in this way, deal constructively with structures and buildings. This article will present, inter alia, a format for inquiry-based learning that could be groundbreaking for architectural education in Germany: the Undergraduate Research Opportunities Program (UROP).

\subsection{Design and Project Orientation as Constraints on Inquiry- Based Learning, as a Special Feature of Architecture}

The education in architectural programs that is offered in Germany at universities of applied sciences, universities, institutions of higher learning, schools of fine art and comprehensive universities is focused on occupational qualification as an "architect," a professional title that is protected by various chamber by-laws. Thus the requirements for vocational training are clearly linked to occupational tasks - primarily the planning of buildings. The Federal Chamber of Architects specifies four main areas of emphasis as occupational tasks in the "Guideline for career qualification - architects" (Leitfaden zur Berufsqualifikation - Architekten, Bundesarchitektenkammer 2007, p. 4, translated):

L. Albrecht, Dipl.-Ing., M.Sc. (殴

Fakultät Architektur + Raumplanung, Technische Universität Wien, Vienna, Austria

e-mail: luise.albrecht@tuwien.ac.at 
- Design, technical, economic, social and ecological planning of buildings as well as urban planning therefor;

- coordination, steering, control of planning and execution of a project;

- consulting as well as support and representation of the client in all matters related to the planning and execution of a construction project;

- the creation of expert reports.

Learning how to design is usually done in the form of project work - in design projects. Naturally, the term project is used very differently within a subject culture. In keeping with the educational reform movements in the 1970s, architectural programs were designed so that they were project-oriented or converted into project-based studies. At the time, the following (groups of) features of a project were identified: Practical and vocational relevance, problem orientation, reference to social reality, interdisciplinarity, complexity of the task (Positionspapier zum Projektstudium im Rahmen der Studienreformdiskussion 1979, pp. 2-3). These features are sometimes included in the current project definitions at various institutions of higher learning; however, in my view, frequently, not all of these components are implemented within the projects. An example of such a reduction is the feature of interdisciplinarity mentioned above. Due to the complexity of building tasks, specialized sectoral planning (such as building services, structural design, etc.) is involved when designing and building. Thus it would be possible to identify a project with an interdisciplinary orientation based on the integration of a project intensification (one of the different directions of sectoral planning), for example, or based on the regular involvement of other disciplines, which is recognizable from the curriculum. A random sampling of study plans at the institutions of higher learning shown in Table 23.1 showed that only a few curricula in bachelor's degree programs in architecture are consistently interdisciplinary.

In the case of project work in a course of studies, different priorities are generally set both in terms of the scale - thus possibly from the smallest object to furnishings, rooms, homes, and even urban districts - and in terms of the orientation of the content, in other words a design with a focus on design detailing, for example. If one examines the curricula in architectural programs, the project (in particular of design projects in the broader sense mentioned above, thus including project intensification) takes up a considerable portion of the program. This article will examine a random sampling of current study plans based on the exam regulations for bachelor's degree programs in architecture at eight German institutions of higher learning in order to determine the percentage and scope of design projects (see Table 23.1). Accordingly, a trend that can be identified in the eight study plans examined is that obligatory design projects in the bachelor's degree account for approximately 30-45 percent. As such, ordinary design projects generally comprise 8-12 credit points; some institutions of higher learning have supplementary modules with $3-5$ credit points in the discipline (for example, for the above-mentioned design detailing). 
Table 23.1 Percentage of design projects in architectural studies

\begin{tabular}{l|l|l|l|l}
\hline University & $\begin{array}{l}\text { Total of } \\
\text { semesters }\end{array}$ & $\begin{array}{l}\text { Total of } \\
\text { credits }\end{array}$ & $\begin{array}{l}\text { Credits per design } \\
\text { project }(\%)\end{array}$ & $\begin{array}{l}\text { Characteristic features: internship, } \\
\text { etc. }\end{array}$ \\
\hline TU Berlin & $6(180)$ & 180 & $81(45 \%)$ & $\begin{array}{l}\text { Design projects and project- } \\
\text { integrated intensification }\end{array}$ \\
\hline UdK Berlin & $8(240)$ & 215 & $93(43 \%)$ & $\begin{array}{l}\text { 5-month office internship (25 LP) } \\
\text { Design projects and impromptu } \\
\text { designs }\end{array}$ \\
\hline HCU Hamburg & $6(180)$ & 180 & $80(44 \%)$ & 1 semester practice phase \\
\hline HTW Konstanz & $6(180)$ & 150 & $54(36 \%)$ & Continued additional modules \\
\hline FH München & $6(180)$ & 180 & $65(36 \%)$ & 2 semesters abroad \\
\hline TU München & $8(240)$ & 180 & $58(32 \%)$ & Includes office internship \\
\hline FH Potsdam & $8(240)$ & 240 & $90(38 \%)$ & $\begin{array}{l}\text { 1 semester option of: Study abroad, } \\
\text { research }\end{array}$ \\
\hline $\begin{array}{l}\text { University of } \\
\text { Stuttgart }\end{array}$ & $8(240)$ & 210 & $70(33 \%)$ &
\end{tabular}

Source: Author's representation, last updated in the fall of 2015

Note: The percentage of the curriculum was determined based on the specified compulsory design projects (including project-integrated intensifications or impromptu designs) within the credit points specified at the home university. Thus phases of study abroad or office internships planned for in the curriculum were not included in the calculation

\subsection{Research and the Understanding of Research in Architecture}

The relationship to research differs so widely in architecture that a rudimentarily uniform understanding of research is not even approximately identifiable or definable. The range in terms of the view of research ranges from statements by architects with reference to their own (designing) actions such as "I design in a research-oriented manner" to the statement that their own actions have nothing in common with research. These statements likely already reflect the complexity of design activities, which has thus far only been understood to some extent in scientific studies (cf. Führ 1999; Ammon \& Froschauer, 2013). According to Banse (1999), in addition to the "stereotypical or routine procedures," design activities have comprised an overlapping of methodical, heuristic and creative intellectual processes.

Since many architects do not consider their own activity to be research-oriented and do not perceive research to be a competence that pertains to their profession, they have a somewhat rejecting attitude towards research. Here, research and scholarship are presumably implicitly equated. Thus this attitude makes the implementation of inquiry-based learning for designing in architecture programs difficult.

In the discipline of architecture, there are numerous fields of research with a scholarly orientation. The group comprising humanities research includes historical, theoretical, cultural-political, artistically oriented disciplines, for example. Also included are designrelated or project-related studies, which must be carried out as a basic examination for 
individual projects (especially in architectural competitions) or as typological research, for example. The "traditional" field of research in architecture, for example in the field of heritage conservation and architectural history, is the building archaeology (e.g. of a historical building or settlement/city). Research in the natural sciences mainly includes technology or material-related topics.

Such research is difficult to implement unless integrated within a design project because of the common curriculum organization in architectural programs outlined above. Research time is almost always included in design projects. A survey of design supervisors at the $\mathrm{FH}$ Potsdam showed that students would invest about 5-30 percent of the working time in research activities. Students' assessment of the percentage of time spent on research was identical in a seminar at TU Wien with approximately 20 participants. The subject areas include studies on the location and/or use in particular. Such preliminary and designrelated activities vary widely, depending on the topic, the sources involved, and the basic design approach. Frequently historical issues and analyses (housing stock, functional relationships, infrastructure, green space) are also included in the subsequent planning. Ultimately, this time spent researching when designing is not referred to as "research," but rather "(preliminary) studies." These studies are also part of the professional practice: They are referenced as "basic evaluation" (Grundlagenermittlung) in the Fee Schedule for Architects and Engineers (HOAI) in Service Phase 1 (special services: "survey, site analysis") (HOAI 2013, Appendix 10). The difference between "research" and "(preliminary) studies" may appear to be marginal in some disciplines; however, architects who implicitly correlate research and science have usually not participated in scholarship within the meaning of a methodological process in their own education and are accordingly unable to pass this experience on.

\subsection{Sample Formats}

Even with the usual basic conditions, in particular a predetermined curriculum and prepared class schedules, inquiry-based learning can be further developed in architectural education. Research questions are frequently handled in many "small" (mandatory) electives, usually comprising 2-4 credit points. "Real research" is frequently divided into partial subjects that lend themselves to processing, which can be worked on by and with students, especially in the theoretical subjects (architectural history, architectural theory, heritage conservation). What is important here is not that students be able to understand their own actions as input to "real research," but rather as a valuable, small building block in the big picture. Frequently, portfolios are required as output from this research that consist of a mixture of graphic, photographic and written documentation. As a general rule (depending on the previous knowledge of the participants and previous courses at school and in the degree program), these research seminars must be accompanied by intensive and methodical support. In many cases, crash courses for research, citation or a writing 
workshop are worth recommending as additional offers. Two developments should be highlighted in conjunction with inquiry-based learning: education research in conjunction with targeted skills development on the one hand, and UROP on the other.

\subsubsection{Peer-Feedback and Student Research Projects}

A few institutions of higher learning have set up special modules in which students can pursue research in the area of architecture, usually instead of a design. At TU Berlin, the corresponding module is called the "student research project" (Lehrforschungsprojekt). As a general rule, all participants in a student research project work "on a shared, predetermined topic. Students work on subtopics within this framework and create a report" (Modulhandbuch 2015, module no.: 60363). This module is only offered within the master's degree, however.

It must be said that a particular weakness of many architecture students is written expressiveness, a competency that is given short shrift in the curricula in architectural programs (cf. Schmitt 2013). "Written expressiveness," as well as "structured thinking" and "analytic capability," can be classified together in the competency category known as cognitive competencies (cf. Hobohm et al. 2015, p. 176) and, without a doubt, form the basis of scholarly work and research. Unlike architectural studies, instructors in the humanities deal intensively with students' texts and deal out constructive criticism of the same. In most architecture curricula, very few texts are written within compulsory courses. Instructors who ask for written reports as proofs of performance often find students' texts "unacceptable" and are unable to remediate the deficit within a seminar. Here, it makes sense that constructive criticism in architectural programs not be limited to a few (and seldom selected) seminars, but to integrate them more frequently and compulsorily in the course of studies. One possibility for integration into the curricula is "peer feedback" (see Box 23.1), in which students provide written constructive criticism of their fellow students' texts.

\section{Box 23.1: Peer Feedback}

Similar to the "peer review" review process for scholarly articles, peer feedback is a review process by members of a specific peer group; in this case, students. In doing so, the students give each other qualitative feedback. In the formalized feedback procedure, students assess the submissions of fellow students based on a questionnaire and, at the end of the process, also receive qualitative feedback on their own submission. The process may be carried out anonymously or with names revealed.

As a general rule, peer feedback is conducted in classes in such a way that students give and receive similar amounts of feedback. The number of feedback responses that they must create (and maintain) is set in advance. It is recommended 


\section{Box 23.1: (continued)}

that there be at least two feedback responses per work output so that students receive different perspectives. In addition to key questions for the assessments, it would be best for rules of constructive feedback to be worked out together with the students so that a positive attitude in the feedback is generally guaranteed.

The method consists of three elements essential to the learning process: (intensively) reading the texts of fellow students, writing feedback and receiving it for their own work. This teaching element can promote (self-)reflection by means of the differentiated assessment of unfamiliar work with an actual/target comparison, which is also carried out in comparison with the work the student has submitted themselves.

In architectural studies, the culture of constructive criticism is usually poorly established. For this reason, students should receive training in which they practice giving constructive criticism based on a similar example before actual feedback responses are given to fellow students. In teaching, the use of online media is an effective strategy for conducting peer feedback. The "Workshop" activity within the e-learning platform Moodle is used for this purpose at the University of Applied Sciences Potsdam (for more detail, see Mauch and Albrecht 2014).

\subsubsection{The Undergraduate Research Opportunities Program (UROP)}

To date, students in bachelor's degree programs in architecture have had barely any curricular opportunity to do their own research. In many cases, the only way for them to participate in scientific research is to work on externally funded projects on a project basis as student assistants. In the United States, the Undergraduate Research Opportunities Program (UROP) was developed to give bachelor's degree students the opportunity to participate in scientific research. A UROP was launched for the first time in 1969 at the prestigious Massachusetts Institute of Technology (MIT) in Boston. Since then, a UROP has been established at almost all US universities; similar programs can be found in Great Britain, Singapore and at RWTH Aachen since 2008.

The respective programs have certain similarities (Laursen et al. 2010, pp. 1-4):

- The research projects are "real science," and thus they are of interest to the scientific community.

- The research project designated for an individual student or a team of students is welldefined in advance and is connected in some way to an ongoing effort in the research group, or to an area of scholarly interest of the supervising researcher. 
- This involves working intensively on the research topics, either as a multi-week immersion, often full-time for 10 weeks during the summer, or over the duration of an entire academic year.

- Individualized guidance is provided by an experienced scientist.

As a rule, projects are publicly announced. Depending on the project and program, students can be credited with academic achievements. Often, the project is associated with financial support. As a rule, these basic conditions can spur the interest of both supervising researchers and bachelor's degree students in participating in the program. In the US, UROPs are an important component of higher education culture, especially when it comes to competing with one another and for the best students. In UROPs, research partnerships are typically concluded within the disciplines. The number of participants in each respective "partnership" varies from project to project, and from program to program, ranging from a partnership of just two to small groups that often have different levels of qualification in the United States: Bachelor's degree students, master's degree students and postdoctoral researchers work together here.

At the University of Applied Sciences Potsdam (FHP), the UROP was conceived and launched by the author as part of the project "FL ${ }^{2}$ Forschendes Lernen - Lehrende Forschung" (FL ${ }^{2}$ inquiry-based learning - instructional research). To date, there have been two nine-month cycles for bachelor's degree students of the three degree programs of the FHP Department of Architecture and Urban Design. Up to five undergraduate students of the department can participate in each cycle and receive professional and financial support. In preparation, and as an important basic condition for amended study and examination regulations, a new option was created: instead of an office internship, students could complete scholarly work in the form of a UROP and receive credit points for this work. It was unclear what interest the program would attract from the students, however. Potential supervising researchers were involved early in the concept. They created short, introductory project descriptions before the respective tenders.

The UROP supervising faculty was also involved in the issue of how and in what medium the research results should be presented. Many institutions of higher learning such as RWTH Aachen University, for example, organize UROP conferences to present the results of their research. Each year, a National Conference on Undergraduate Research (NCUR) is held in the United States at which undergraduate students present their research results (more than 3000 presentations). Supervisors and students at FH Potsdam prefer that students make their own first publication as a result presentation of their UROP research, which of course does not exclude extending this to include presentations and conferences. The scope of the publication approximately corresponds to a typical journal article. Deadlines were set to allow the UROP research to be published in a joint publication. Students can freely select the phase during which this research is done; depending on the degree program and the semester, this research falls into different time periods. 
Since, as a rule, this is the first time that architecture students will have the opportunity to go through an entire research process, supervisors should not expect any previous research knowledge. The author of this article set up a supervisory colloquium in Potsdam in order to support those who are new to research. This offers both general methodological assistance in research beyond subject-specific and topic-specific questions, and opportunities for exchanges among UROP participants. Depending on the focus of the ongoing UROP projects being worked on, research competencies - starting with the limitation of the topic, and ranging from researching strategies and writing a synopsis to support in obtaining the image rights for the publication - are discussed and strengthened at the colloquia, which are held on a monthly basis. If content-related decisions are also made within the supervisory colloquium (for example, a specifically developed research question), the specific research supervisors are informed, and the students are asked to discuss content-related decisions with these experts. In the long term, as soon as a UROP culture is established in a university, a program similar to MIT's "Research Mentor Program" could be set up, in which experienced UROP students support those who are new to UROP.

\subsection{Outlook}

At the moment, institutions of higher learning are placing increased pressure on architecture departments or faculties to do more research, and in particular to attract more external funding. In response to this, research conferences have been and are being initiated at some institutions of higher learning (for example TU Berlin, BTU Cottbus, TU Darmstadt, TU Vienna). In Switzerland, all ten architecture colleges met in 2015 for a joint research conference (Solt 2015, p. 12). Such events are primarily aimed at increasing the visibility of architectural research and partly at representing what architectural research is understood to be. Networking is usually a goal as well. Research conferences form an important component in the establishment of research in architecture. Without "real" research interests, without research practice in the sense of a methodical process, inquiry-based learning is difficult to establish and pass on.

A changed attitude towards research in architecture could and should begin much earlier, preferably as soon as the study begins. In the first week of a pilot project implemented at FH Potsdam by the author, new students were encouraged to develop open research questions associated with a building survey and drafting exercise at Potsdam's Belvedere on the Pfingstberg. This assignment provides instructors with a great deal of insight. They are able to get to know a variety of unexpected questions that new student have with regard to architecture, many of which could unexpectedly be approached in an interdisciplinary way (although answering most questions would exceed the scope of a dissertation). For the new students, this exercise provides an insight into the variety of possible topics in the selected subject area. At the same time, this exercise aims to detect an individual's own 
areas of interest and support curiosity - an important moment in the research process. Research-based learning and teaching could be further developed by means of a variety of even smaller teaching elements across all phases of architectural studies.

In order to bring about long-term changes, UROPs need to be further developed and strengthened. The aim of this expansion would be to ensure that the up-and-coming next generation is more likely to have come to know research in the sense of a methodological process even during their studies. Establishing research in architecture would have numerous benefits: a financial benefit for the institutions of higher learning in terms of attracting external funding, an individual benefit for each graduate in personally developing a critical (research) attitude, and the professional benefit of a methodical process for the basic evaluation and "preliminary investigations" in architecture.

\section{References}

Banse, G. (1999). Entwerfen im Spannungsfeld von Methodik, Heuristik und Kreativität. Wolkenkuckucksheim: internationale Zeitschrift für Theorie und Wissenschaft der Architektur, 4(1), Retrieved 10 July 2015 from http://www.cloud-cuckoo.net/openarchive/wolke/deu/ Themen/991/Banse/banse.html

Bundesarchitektenkammer (2007). Leitfaden Berufsqualifikation der Architekten/innen. Retrieved 10 July 2015 from http://www.bak.de/architekten/ausbildung/leitfaeden-zur-berufsqualifikation/ leitfaden-zur-berufsqualifikation-architekten-1.pdf

Führ, E. (Hrsg.). (1999). Entwerfen - Kreativität und Materialisation. Wolkenkuckucksheim: internationale Zeitschrift für Theorie und Wissenschaft der Architektur, 4(1).

HOAI (2013). Verordnung über die Honorare für Architekten- und Ingenieurleistungen (Honorarordnung für Architekten und Ingenieure - HOAI) Anlage 10 (zu § 34 Absatz 4, § 35 Absatz 7) Grundleistungen im Leistungsbild Gebäude und Innenräume, Besondere Leistungen, Objektlisten. Retrieved 10 July 2015 from http://www.gesetze-im-internet.de/hoai_2013/ anlage_10.html

Hobohm, H.-C./Pfeffing, J./Imhof, A./Groeneveld, I. (2015). Reflexion als Metakompetenz. Ein Konzeptbegriff zur Veranschaulichung akademischer Kompetenzen beim Übergang von beruflicher zu hochschulischer Qualifikation in den Informationsberufen. In W. Freitag/R. Buhr/ E.-M. Danzeglocke/S. Schröder/D. Völk (Hrsg.), Übergänge gestalten: Durchlässigkeit zwischen beruflicher und hochschulischer Bildung erhöhen (S. 173-191). Münster: Waxmann.

Laursen, S./Hunter, A.-B./Seymour, E./Thiry, H./Melton, G. (Hrsg.). (2010). Undergraduate Research in the Sciences: Engaging Students in Real Science. New York, NY: John Wiley \& Sons.

Mauch, M./Albrecht, L. (2014). Online-gestütztes Peer-Feedback als Baustein Forschenden Lernens. In N. Apostolopoulo/H. Hoffmann/U. Mußmann/W. Coy/A. Schwill (Hrsg.), Grundfragen Multimedialen Lehrens und Lernens. Der Qualitätspakt E-Learning im Hochschulpakt 2020. Tagungsband GML 2014 (S. 265-280). Münster: Waxmann.

Modulhandbuch WiSe 2015/16 für Studiengang Architektur Master StuPO2011 (2015). Retrieved 10 July 2015 from http://www.planen-bauen-umwelt.tu-berlin.de/fileadmin/f6/Studieng_nge/01_ Modulkataloge/Arch_M_StuPO2011_WiSe15-16.pdf 
Positionspapier zum Projektstudium im Rahmen der Studienreformdiskussion (1979). Tagung: Projektstudium für Bauingenieurwesen, Architektur und Raumplanung, Dortmund.

Schmitt, G. (2013). Mehr Schreibkompetenz für Planer und Architekten. Arbeitsmarkt Umweltschutz und Naturwissenschaften, 21(43), 6-8.

Solt, J. (2015). Was ist Architekturforschung? Tec21: Fachzeitschrift für Architektur, Ingenieurwesen und Umwelt, 15, 12.

Open Access This chapter is licensed under the terms of the Creative Commons AttributionNonCommercial-NoDerivatives 4.0 International License (http://creativecommons.org/licenses/bync-nd/4.0/), which permits any noncommercial use, sharing, distribution and reproduction in any medium or format, as long as you give appropriate credit to the original author(s) and the source, provide a link to the Creative Commons licence and indicate if you modified the licensed material. You do not have permission under this license to share adapted material derived from this chapter or parts of it.

The images or other third party material in this chapter are included in the chapter's Creative Commons licence, unless indicated otherwise in a credit line to the material. If material is not included in the chapter's Creative Commons licence and your intended use is not permitted by statutory regulation or exceeds the permitted use, you will need to obtain permission directly from the copyright holder.

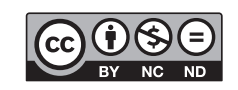

